\title{
DIAGNÓSTICOS DE MANIFESTAÇÕES PATOLÓGICAS EM ESTRUTURAS DE CONCRETO ARMADO CAUSADAS POR ERROS EXECUTIVOS
}

\author{
CARDOSO, RAIANY \\ Acadêmica de Engenharia Civil \\ Universidade Federal de Rondônia - UNIR \\ Rondônia; Brasil \\ raianycrds@gmail.com
}

\author{
JARDIM, PEDRO I. L. G \\ Acadêmico de Engenharia Civil \\ Universidade Federal de Rondônia-UNIR \\ Rondônia; Brasil \\ pedro@unir.br
}

\author{
RIBEIRO, LÍVIA M P. \\ Professora do Magistério Superior \\ Universidade Federal de Rondônia - UNIR \\ Rondônia; Brasil \\ livia.ribeiro@unir.br
}

\author{
TUTIKIAN, BERNARDO F \\ Coordenador do ITT Performance \\ Universidade do Vale do Rio dos Sinos \\ Rio Grande do Sul; Brasil \\ bftutikian@unisinos.br
}

\section{RESUMO}

No desenvolvimento das etapas de uma obra, pode-se observar falhas recorrentes em uma ou mais fases da mesma, podendo dividi-las em: elaboração dos projetos, execução e utilização da estrutura. Considerando os erros comumente encontrados durante a execução de estruturas de concreto armado, é cabível considerar que existam algumas deficiências no processo construtivo que motive tais ocorrências, como: a falta de capacitação de profissionais para concepção e análise de estruturas, procurando prever pontos críticos; e a falta de um planejamento prévio e gerenciamento eficazes para que uma estrutura desempenhe de forma adequada ao longo da sua vida útil a função para qual foi projetada, atendendo os preceitos normativos vigentes. Para uma correta análise, recuperação e prevenção dessas manifestações patológicas ocorridas nas estruturas de concreto armado é necessário diagnosticá-las. Dessa forma, neste trabalho serão ressaltadas as principais causas dessas manifestações, fazendo a correlação bibliográfica com artigos técnicos e acadêmicos, literatura tradicional e normas técnicas, procurando identificar recomendações quanto aos métodos executivos de estruturas de concreto armado convencional que possuam propensão de surgimento de manifestações patológicas em virtude dessa má execução, destacando ainda as possíveis causas e soluções. Palavras-chave: Patologia, estruturas, execução e planejamento.

\begin{abstract}
In the development of the stages of a construction, recurring failures can be observed in one or more phases of the work, and can be divided into: project design, execution and use of the structure. Considering the errors commonly encountered during the execution of reinforced concrete structures, it is appropriate to consider that there are some deficiencies in the construction process that motivate such occurrences, such as: lack of training of professionals for design and analysis of structures, seeking to predict critical points; and the lack of effective prior planning and management for a structure to perform adequately throughout its useful life the function for which it was designed, in compliance with current regulatory precepts. For a correct analysis, recovery and prevention of these pathological manifestations occurred in reinforced concrete structures it is necessary to diagnose them. Thus, this work will highlight the main causes of these manifestations, making the bibliographic correlation with technical and academic articles, traditional literature and technical standards, seeking to identify recommendations regarding the executive methods of conventional reinforced concrete structures that have a propensity to appear pathological manifestations due to this poor execution, highlighting the possible causes and solutions Keyword: Pathology, structures, execution and planning
\end{abstract}

\section{INTRODUÇÃO}

A construção civil abrange diversas etapas desde a fase do início das ideias à execução dos projetos. Durante esse percurso é possível observar um número de falhas recorrentes em uma ou mais fases, sendo divididas basicamente em: elaboração dos projetos, execução e utilização da estrutura executada.

De acordo com Helene (2003), a segunda maior causa das manifestações patológicas atribui-se aos erros de execução. 
Mais precisamente, o autor afirma que $40 \%$ das manifestações patológicas são provenientes de projetos inadequados, seguidos por $28 \%$ de problemas na execução, $18 \%$ pelo uso de materiais de baixa qualidade, $10 \%$ pela má utilização da edificação e $4 \%$ pelo mau planejamento.

Com isso, é possível observar que existe uma deficiência na construção civil que ocasiona erros executivos. A falta de capacitação da equipe técnica e operacional pode ser citada como exemplo de investimento por vezes negligenciado. A capacitação de profissionais para análise de estruturas, procurando prever as possíveis manifestações patológicas que podem ocorrer, e utilizar as técnicas de prevenção mais adequadas é uma modalidade de capacitação que visa melhoria da qualidade técnica do produto final, redução de tempo de execução com a diminuição de retrabalhos, dentre outras vantagens. Além disso, é possível levar em consideração a falta de cuidados condições de trabalho, falta de controle de qualidade, má qualidade de materiais e equipamentos e irresponsabilidade técnica.

Segundo Gonçalves (2015), as manifestações patológicas não têm sua origem concentrada em fatores isolados, mas sofrem influência de um conjunto de variáveis, que podem ser classificadas de acordo com o processo patológico, com os sintomas, com a causa que gerou o problema ou ainda a etapa do processo produtivo em que ocorrem, além de apontar para falhas também no sistema de controle de qualidade próprio a uma ou mais atividades.

A ocorrência de um problema patológico se associa a falhas ocorridas durante a realização de uma ou mais etapas da construção, seja no projeto, na execução ou na utilização da edificação e podem manifestar-se após o início da obra, durante a realização, a fase de uso ou após anos de conclusão da obra. Sendo assim, com o intuito de identificar e classificar corretamente estas anomalias surge a Patologia das Estruturas, a qual se ocupa do estudo das origens, causas, sintomas e dos mecanismos de ocorrência dos problemas nas construções civis (SANTOS, 2014).

Dessa forma, para uma maior compreensão das principais manifestações patológicas nas estruturas de concreto armado durante sua execução, torna-se necessário analisar as tipologias recorrentes e diagnosticar suas possíveis causas. Após o diagnóstico é possível propor medidas para recuperação estrutural ou qualquer outro método para solucionar tais processos de deterioração, com base nas principais normas utilizadas para projetar e executar estruturas de concreto da forma correta. Ao final é possível sugerir medidas preventivas que devem ser adotadas para garantir a segurança estrutural e evitar consumos elevados em reparos que podem ser anulados ou amenizados.

Por muito tempo o concreto foi considerado um material extremamente durável, devido a algumas obras muito antigas ainda encontrarem-se em bom estado, porém a deterioração precoce de estruturas recentes remete aos porquês das manifestações patológicas do concreto (BRANDÃO \& PINHEIRO, 1999). Lottermann (2013) afirma que até o final da década de 80, a resistência à compressão ainda era, praticamente, o único parâmetro adotado para avaliar a qualidade do concreto. Em função disto, está ocorrendo uma degradação mais acelerada nas estruturas de concreto armado, obrigando a comunidade que trabalha com este material a definir novos parâmetros, de forma a garantir seu desempenho.

Ainda, Lottermann (2013) destaca que os processos principais que causam a deterioração do concreto podem ser agrupados, de acordo com sua natureza, em mecânicos, físicos, químicos, biológicos e eletromagnéticos. Os processos de degradação alteram a capacidade de o material desempenhar as suas funções, e nem sempre se manifestam visualmente. $\mathrm{Na}$ realidade a deterioração do concreto ocorre muitas vezes como resultado de uma combinação de diferentes fatores externos e internos. Os três principais sintomas que podem surgir isoladamente ou simultaneamente são: a fissuração, o destacamento e a desagregação.

Sendo assim, destaca-se a fase de execução como a segunda responsável pela causa de manifestações patológicas estruturais. Segundo Gonçalves (2015), os responsáveis pela execução de um projeto de edificação devem atentar para as decisões que serão tomadas durante o processo construtivo, como a compra de materiais, ou nas formas de execução. Nesta etapa, devem ser tomados todos os cuidados necessários ao bom andamento da construção, com a indispensável caracterização da obra, individualizada pela programação de atividades, alocação de mão-de-obra, definição do "layout" do canteiro e previsão de compras dos materiais (SOUZA e RIPPER, 1998). A NBR 14931 (ABNT, 2004) define como execução da estrutura de concreto todas as atividades desenvolvidas na sua execução, ou seja, sistema de fôrmas, armaduras, concretagem, cura e outras, bem como as relativas à inspeção e documentação de como construído, incluindo a análise do controle de resistência do concreto. Falhas construtivas durante a etapa de execução da obra podem causar repercussões danosas ao desempenho da estrutura de concreto. 
Souza e Ripper (1998) afirmam que a ocorrência de problemas patológicos cuja origem está na etapa de execução é devida, basicamente, ao processo de produção, que reflete de imediato nos problemas socioeconômicos, que provocam baixa qualidade técnica dos trabalhadores menos qualificados, como os serventes e os meio-oficiais, e mesmo do pessoal com alguma qualificação profissional. Assim como, também, a falta de uma fiscalização eficiente e um fraco comando de equipes podem, com facilidade, levar a falhas graves em determinadas atividades como, escoramentos, fôrmas, posicionamento e qualidade das armaduras, qualidade do concreto, entre outras (COUTO, 2007).

Em todas as construções, que tem sua estrutura executada em concreto, fissuras podem surgir depois de anos, dias ou mesmo horas. As causas destas fissuras são várias e de diagnóstico difícil. O termo fissura é utilizado para designar a ruptura ocorrida no concreto sob ações mecânicas ou físico-químicas (FIGUEIREDO, 1989).

A fissuração pode ser considerada a manifestação patológica mais recorrente, ou pelo menos, a que chama mais atenção dos proprietários (SOUZA e RIPPER, 1998). As trincas podem começar a surgir, de forma congênita, logo no projeto arquitetônico da construção. Os profissionais ligados ao assunto devem se conscientizar de que muito pode ser feito para minimizar o problema, pelo simples fato de reconhecer que as movimentações dos materiais e componentes das edificações civis são inevitáveis (THOMAZ, 1989). A movimentação por dilatação térmica é a tipologia mais comum encontrada nas construções. Dal Molin (1988) retrata que, entre os principais tipos de fissuras existentes, 10,49\% pertence aos detalhes construtivos.

Diante disso, este estudo visa realizar um diagnóstico de manifestações patológicas causadas devido às falhas construtivas durante a execução de uma estrutura de concreto armado na cidade de Porto Velho/RO. Ainda, objetiva definir soluções específicas para a recuperação da estrutura, bem como as medidas preventivas cabíveis.

\section{MÉTODO}

Este trabalho tem seu desenvolvimento baseado em uma revisão bibliográfica sobre as causas de manifestações patológicas mais comuns em estruturas de concreto armado ocorridas durante sua execução, o processo de análise e posterior diagnóstico e a solução dos problemas patológicos encontrados. O levantamento de dados e informações foi realizado por meio de pesquisa eletrônica via internet e livros dos autores mais reconhecidos no ramo da engenharia civil. A revisão deu ênfase especial às manifestações patológicas de estruturas de concreto armado, englobando causas, forma de manifestação, prevenção e cuidados especiais, manutenção e inspeção. As duas edificações analisadas, A e B, estão localizadas na região do Município de Porto Velho- Rondônia, em um condomínio. São constituídas de estruturas de concreto armado e possuem manifestações patológicas estruturais aparentes para análises.

A estrutura e os tipos de manifestações patológicas recorrentes nas estruturas dos edifícios foram estudados para realização do diagnóstico abordando as causas, o método de recuperação mais adequado e ainda, as formas de prevenção. A coleta de dados das manifestações patológicas foi exclusivamente destinada às estruturas de concreto armado aparente.

O procedimento metodológico para estudo das estruturas de concreto armado, após a definição das edificações e a determinação das estruturas para análise e estudo, foi primeiramente o levantamento das manifestações patológicas nas estruturas de concreto armado. Em seguida, o procedimento para identificação das causas e, ainda, as conclusões que é a etapa final, a qual se analisou a situação no caso e, por fim, definiu-se as soluções possíveis para os problemas e em seguida, abordadas medidas preventivas viáveis.

\section{ESTUDO DE CASO}

Neste item, foi apresentado um estudo de caso teórico sobre as principais manifestações patológicas encontradas em um condomínio, possuindo duas edificações A e B, através do levantamento fotográfico das manifestações patológicas, indicando sua respectiva localização na edificação, bem como a descrição por inspeção visual, as manifestações patológicas detectadas, indicação das prováveis causas juntamente com a descrição do diagnóstico, soluções específicas e medidas preventivas para cada manifestação patológica.

Cada edificação possui quatro pavimentos, incluindo o térreo e cobertura, 28 apartamentos, sendo entregue no início do ano de 2014. Os métodos construtivos adotados constituem: sistema pilotis, ou seja, a edificação é sustentada através de uma grelha de pilares em seu pavimento térreo; alvenaria convencional e lajes maciças armadas em duas direções. 


\subsection{Análise do Prédio A}

Após inspeção visual realizada in loco observou-se a presença de manifestações patológicas na cobertura do prédio. A localização externa do ambiente que possui as manifestações patológicas encontradas foi demonstrada nas figuras 1 a 5.

Figura 1: Localização externa do ambiente que possui as manifestações patológicas encontradas.

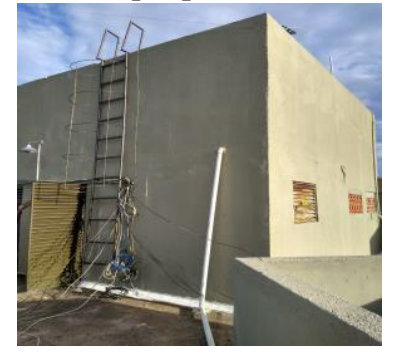

Fonte: Autores, 2020.

Figuras 2 e 3: Laje de sustentação dos reservatórios que abastecem o Prédio A, parte exposta.
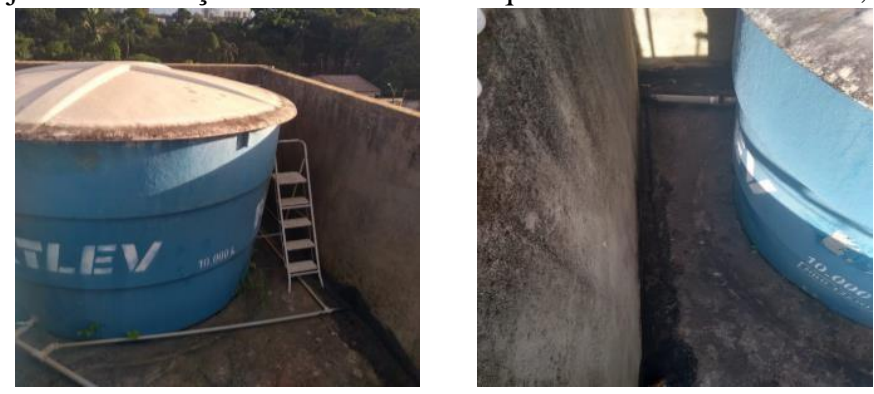

Fonte: Autores,2020.

Figuras 4 e 5: Laje de sustentação dos reservatórios que abastecem o Prédio A, parte interna.
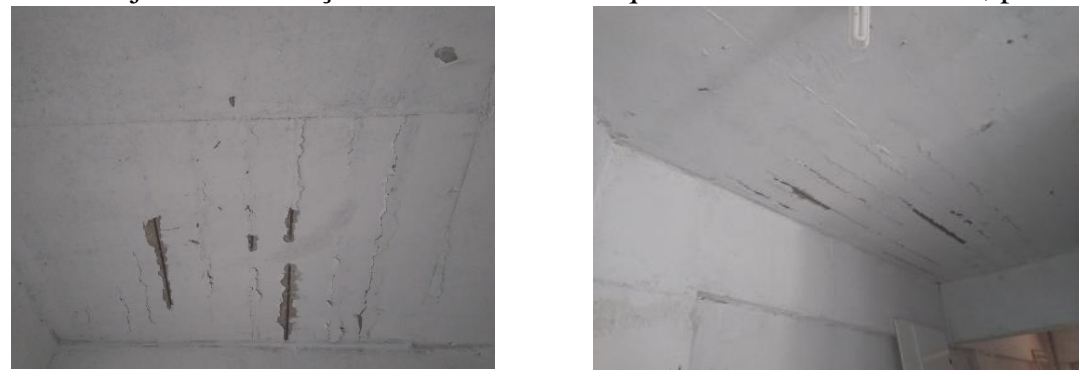

Fonte: Autores, 2020.

A manifestação encontrada na laje de cobertura do Prédio A, a qual sustenta os reservatórios que abastecem a edificação, foi de corrosão da armadura e manchas de umidade. Existe evidências de má execução na concretagem, insuficiência de cobrimento da armadura e falha no sistema de impermeabilização. Ou seja, as fissuras encontradas tiveram possível origem devido às variações de umidade, visto que o prédio está totalmente exposto a intempéries por não receber o tratamento de impermeabilização adequado.

A infiltração foi a principal causa dos danos nos elementos, pois ocorreu abundantemente na estrutura, visto que o edifício não possui cobertura, recebendo todo os volumes de água da chuva diretamente na laje que não possui impermeabilização adequada, o que foi gerando danos à estrutura. Dessa forma, o diagnóstico da manifestação é de corrosão das armaduras da laje de sustentação dos reservatórios, no Prédio A. Ou seja, houve a perda de seção das barras de aço e concomitante a esta perda de seção formaram-se produtos de corrosão de caráter expansivo no entorno das armaduras que vão se 
acumulando e gerando tensões internas não previstas em projeto as quais acabaram fissurando o concreto e sequencialmente lascando-o e destacando-o, deixando, assim, a armadura totalmente exposta aos seus agentes agressores, o que acelera ainda mais o processo corrosivo (CASCUDO, 2005).

Para este caso, as soluções específicas são: remover o concreto afetado e os produtos da corrosão; reconstituir a seção original da armadura (se comprovada a perda de seção transversal ou rompimento); na presença de agentes agressivos, efetuar a correção com primer (pintura anticorrosiva); reforçar o componente estrutural aumentando as dimensões originais (garantir cobrimento adequado). A profilaxia indicada é a construção uma cobertura adequada para os reservatórios e impermeabilizar corretamente a laje de sustentação.

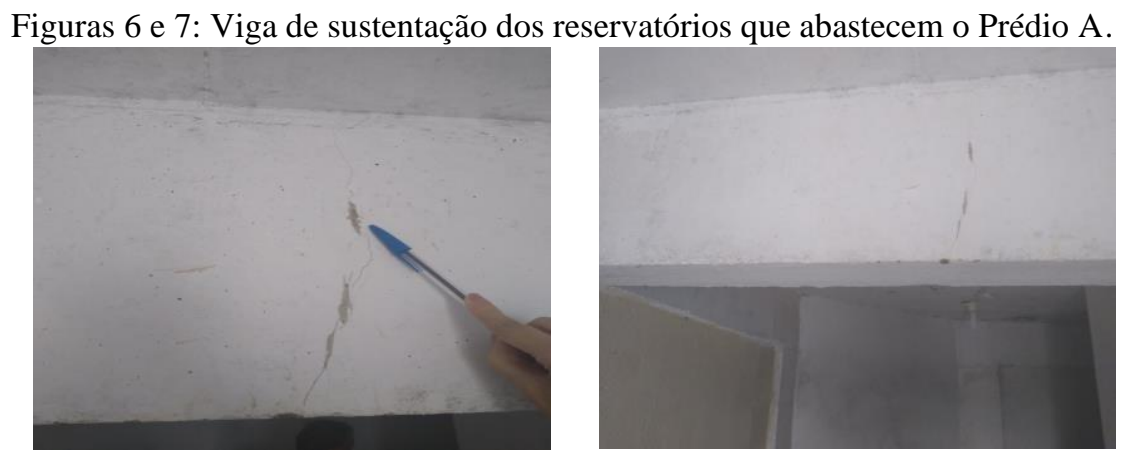

Fonte: Autores, 2020.

A manifestação patológica localizada na viga coberta do Prédio A (figuras 6 e 7), a qual sustenta os reservatórios que abastecem a edificação, foi de fissuras verticais localizadas no trecho central da viga em relação aos apoios. Segundo Thomaz (1989), pode-se caracteriza-las como fissuras de flexão, ou seja, que se localizam perpendicularmente aos esforços de tração, sendo praticamente verticais no terço médio do vão e possuem aberturas maiores em direção à face interior no qual a viga está sofrendo maior valor de tração. Trindade (2015) afirma que tem como fator causador a insuficiência de armadura responsável por resistir à tração, o erro pode ter ocorrido na concepção do projeto ou na execução, tanto por negligência, como por falta de conhecimento. O condomínio não dispunha do projeto estrutural do edifício. Para uma melhor verificação da suficiência das armaduras, deve-se verificar com equipamentos de ultrassom e pacometria a taxa de aço nesses elementos, bem como a fissuração interna. Outro possível fator causador dessas fissuras é a movimentação térmica ou retração por dessecação superficial, ocasionadas por um processo de cura inadequado.

Segundo Lotterman (2013), para uma solução adequada faz-se uma análise do grau em que se encontra a trinca. Devemse fazer testes para diagnosticar se a trinca é progressiva, ou seja, se existe uma progressão da abertura com o passar do tempo, bem como uma análise estrutural completa para então saber se há necessidade de fazer um reforço na viga. Segundo o mesmo autor, existem aparelhos que permitem medir a variação dessas aberturas, como fissurômetros, que são colocados sobre as fissuras constituídos por calços de gesso, tiras de vidro ou de papel, que apenas permitem detectar, grosseiramente, eventuais acréscimos da abertura. Caso houver necessidade da aplicação de um reforço na viga, existem alternativas como mantas de fibra de carbono, adoção de perfil metálico e até um encamisamento da estrutura antiga com concreto armado nas regiões tracionadas da viga.

Figuras 8 e 9: Laje de cobertura do Prédio A.

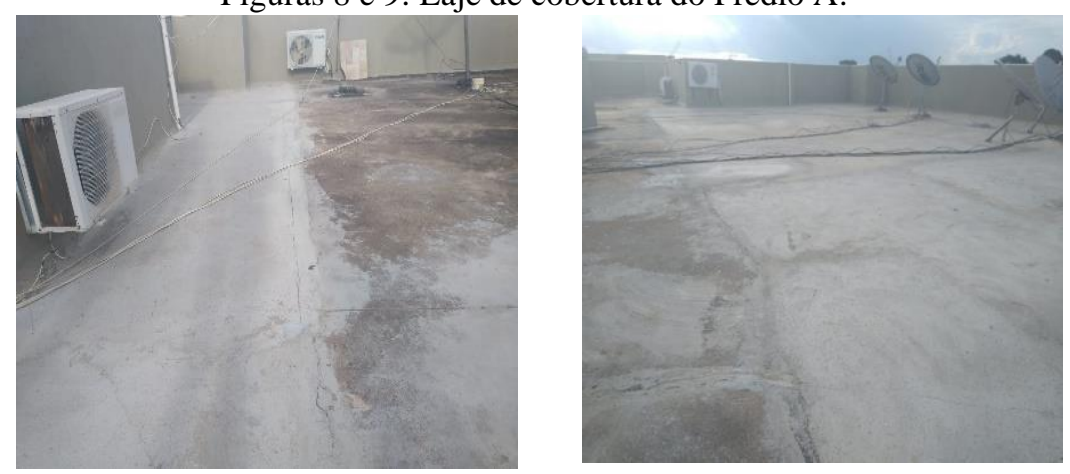

Fonte: Autores, 2020. 
A manifestação localizada na laje de cobertura do Prédio A (figuras 8 e 9) apresenta fissuras paralelas, caracterizando retração plástica. Segundo Trindade (2015), essa manifestação ocorre quando o concreto ainda está em sua fase plástica, logo após o lançamento do concreto nas formas e tem como fator principal a rápida perda de água. Os agregados graúdos e miúdos, devido a maior densidade, acabam por descer e a água sobe para superfície, o que é chamado de exsudação. Esta água acaba por ser evaporada, tanto mais rápido, quando maior for a temperatura, menor umidade e maior a ação do vento. Para este caso, a solução indicada é realizar o selamento, a fim de proteger as armaduras de ataques de agentes externos, que poderão infiltrar por meio das fissuras. Ou seja, construir uma cobertura adequada para os reservatórios e impermeabilizar corretamente a laje de sustentação. Esta manifestação pode ser evitada se, na etapa de execução, for feita a cura apropriada. Segundo Marcelli (2017), recomenda-se que o período mínimo de cura seja de 7 a 10 dias, mantendo o concreto úmido o tempo todo.

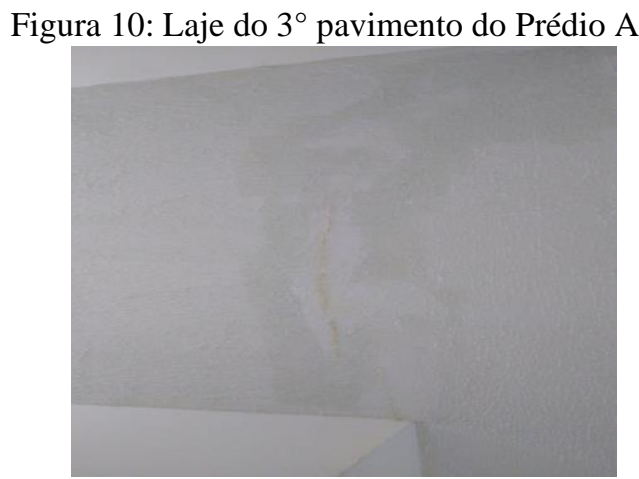

Fonte: Autores, 2020.

A manifestação encontrada na laje do terceiro pavimento do Prédio A (figura 10) indica infiltração ocasionando o início do processo de corrosão pela expansão da armadura, e desplacamento do concreto. O surgimento da corrosão ocorreu devido a presença de oxigênio, umidade e o estabelecimento de uma célula de corrosão eletroquímica (IANTAS, 2010). Esta pode ser ocasionada por deficiência da impermeabilização do reservatório de água da edificação e por erros de descrição do serviço no projeto. Quando não há absorção suficiente da água, há o desprendimento dos materiais, devido ao excesso de água. Esse excesso de água pode ser devido a chuvas intensas no local ou pelo mecanismo de capilaridade quando aparece em interiores de residenciais como este, trazendo consigo o deslocamento das pinturas. O deslocamento da pintura como mostra a figura tem sua ocorrência devido à reação de sais das eflorescências, que lixiviados até a interface da pintura, prejudicam a aderência, acarretando seu descolamento. Como solução, indica-se a eliminação definitiva da umidade no local, devido às falhas na impermeabilização, e pode ser obtida com a injeção de produtos cristalizantes em furos executados nas bases do local danificado de modo a impedir a ascensão da umidade por capilaridade.

Recomenda-se construir uma cobertura adequada para os reservatórios e impermeabilizar corretamente a laje de sustentação.

\subsection{Análise do Prédio B}

Após inspeção visual observou-se a ocorrência de manifestações patológicas na cobertura do prédio e na garagem do pavimento térreo. A localização externa do ambiente que possui as manifestações patológicas encontradas será demonstrada nas figuras 11 e 12 . 
Figura 11: Laje de cobertura do Prédio B.

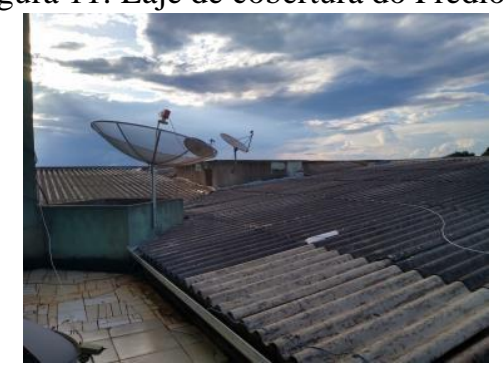

Fonte: Autores, 2020.

Figura 12: Janela Prédio B.

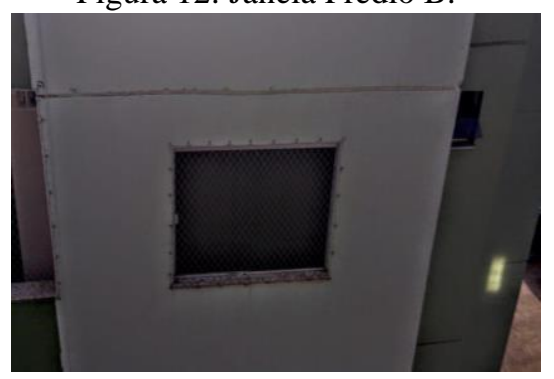

Fonte: Autores, 2020.

As manifestações patológicas encontradas nas janelas do Prédio B foram de fissuras a 45 graus tanto na parede de alvenaria quanto na cerâmica, partindo dos cantos das esquadrias, local onde os esforços de tração são mais intensos. Esse comportamento indica a esforços superiores aos admitidos para as vergas e contravergas executadas no local, caso existam.

As fissuras por sobrecarga em torno de aberturas ocorrem em paredes de alvenaria descontínuas, ou seja, com uma ou mais aberturas, submetidos a carregamentos de compressão e têm como característica a formação de fissuras a partir dos vértices das aberturas (THOMAZ, 1989). Nas continuidades ocorrem esforços de flexão e cisalhamento, comumente suportados por vigas. Para distribuir esse carregamento para a alvenaria utiliza-se vergas e contravergas. Para os casos que a execução desses elementos seja feita de forma a não suportar essas ações e distribuir para os elementos subjacentes é comum o surgimento das fissuras descritas anteriormente. Essas fissuras podem apresentar-se com diversas configurações, em função de diversos fatores como dimensão da parede e aberturas, materiais constituintes das paredes, dimensão e rigidez de vergas e contravergas, deformação e comportamento da alvenaria e de seu suporte. Destaca-se a provável má execução das vergas e contravergas.

Os vãos na alvenaria que recebem janelas e portas são considerados regiões de concentração de tensões. Para reduzir o risco de surgirem fissuras nas paredes, é preciso, portanto, promover a distribuição das cargas. Isso é obtido com o uso das vergas e contravergas, normalmente em concreto armado, do ultrapassando no mínimo $30 \mathrm{~cm}$ dos limites da esquadria. A profilaxia indicada é a verificação, por meio de equipamentos de pacometria, da existência de vergas e contravergas e, caso existam, proceder com o reforço das mesmas. 
Figuras 13 e 14: Fissuras horizontais de paredes localizadas na cobertura do Prédio B.
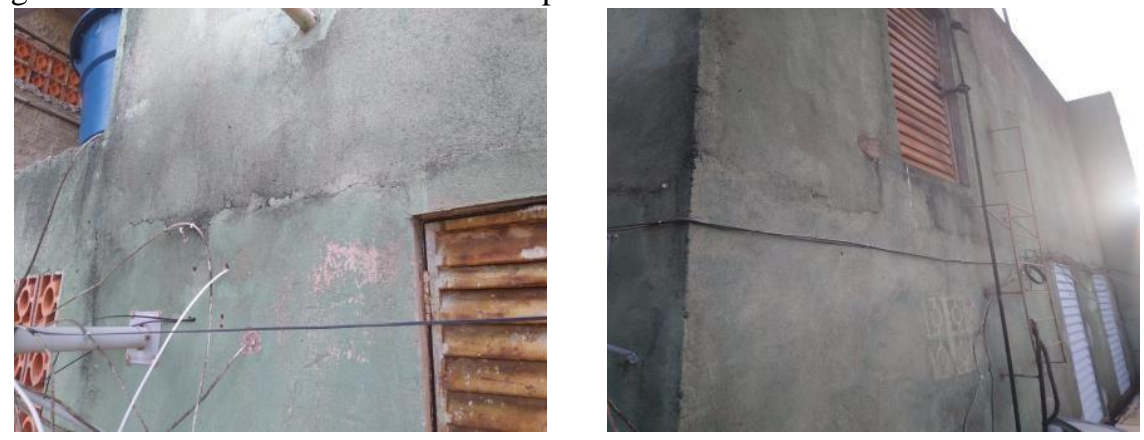

Fonte: Autores, 2020.

A manifestação localizada nas paredes localizadas na laje de cobertura do Prédio B (figuras 13 e 14) são de fissuras horizontais nas juntas entre a alvenaria e a viga, características de movimentação térmica diferencial, sendo causadas pelos ciclos de umedecimento e secagem de argamassa de revestimento, com deficiente impermeabilização da superfície, associados às próprias movimentações térmicas do revestimento provocam inicialmente a formação de microfissuras na argamassa. Através destas ocorrerão penetrações de água cada vez maiores, acentuando-se progressivamente as movimentações e a consequente incidência de fissuras no revestimento. O processo executivo da alvenaria sob a viga, quando não executando de forma a garantir a correta cura da argamassa favorece o surgimento desses problemas. A execução da etapa de impermeabilização com técnica inadequada contribui fortemente para o surgimento e agravamento das manifestações patológicas tendo em vista a possibilidade do contato da estrutura e da alvenaria com agentes agressivos externos. O diagnóstico dessa manifestação é de fissuras causadas por movimentação térmica.

Como solução, deve-se realizar a técnica de bandagem. Conforme salienta Casotti (2007), as etapas de recuperação da fissura com bandagem serão as seguintes: remoção do revestimento da parede, numa faixa com largura de aproximadamente 10 a $15 \mathrm{~cm}$; aplicação da bandagem com distribuição regular para ambos os lados da fissura; aplicação de chapisco externamente à bandagem e recomposição do revestimento com argamassa com baixo módulo de revestimento (traço 1:2:9 em volume);

Em todos os casos, o princípio de funcionamento da recuperação com bandagem é a absorção da movimentação da fissura por uma faixa de revestimento relativamente larga não aderente à base, desta forma, quanto melhor a dessolidarização promovida pela bandagem e quanto maior for sua largura, menores serão as tensões introduzidas no revestimento pela variação na abertura da fissura e, portanto, menor a probabilidade da fissura voltar a pronunciar-se no revestimento. Como profilaxia, deve-se realizar a redução da insolação sobre a alvenaria e substituição das juntas de assentamento.

Figuras 15 e 16: Infiltração no pilar da garagem do Prédio B.

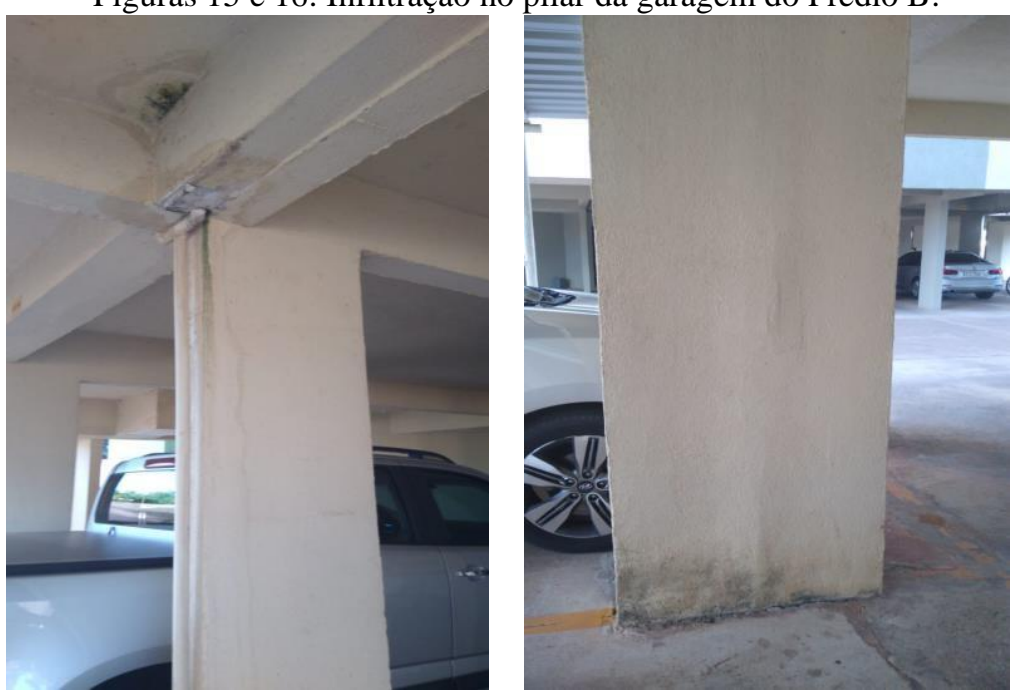

Fonte: Autores, 2020. 
Foi encontrada a presença de eflorescência e manchas de umidade em pilares da garagem do Prédio B (Figuras 15 e 16). Segundo Gonçalves (2015), a eflorescência é a formação de depósitos salinos na superfície do concreto, resultante da água de infiltrações ou intempéries. Esses sais constituintes podem ser agressivos e causar desagregação profunda, além da modificação do aspecto visual na estrutura, pois há um contraste de cor entre os sais e o substrato sobre os quais se depositam, conforme pode-se observar na figura. Conforme Silva (2011), a situação de infiltração e umidade na estrutura é um forte estimulador para que microrganismos se proliferem na mesma, implicando no surgimento de manchas esverdeadas denominadas bolor (fungos), na pesquisa em específico 16,67\% das obras apresentaram essa manifestação. Esse problema é agravado principalmente pela falta de manutenção nas estruturas.

A principal causa para essa ocorrência é a falha no sistema de impermeabilização. Ou seja, a falta de proteção contra a umidade e deficiência na drenagem superficial da região em destaque, acarretou o acúmulo de águas retidas pelo elemento que conecta os pilares, o que é explicado pela presença dos sintomas patológicos na região da base dos mesmos. $\mathrm{O}$ diagnóstico para essa manifestação é de lixiviação do concreto.

Como solução indica-se a limpeza da estrutura e em seguida utilização de ácidos, como ácido sulfônico, ácido amido sulfônico ou removedores de materiais. Como medida preventiva, recomenda-se a utilização de impermeabilizantes sobre substratos com argamassa de revestimento sem cal.

\section{CONCLUSÃO}

As manifestações patológicas presentes nas estruturas que ocorrem por falta das corretas providencias das etapas da obra, além de atribuírem à construção uma imagem estética negativa, desvalorizando o imóvel, contribuem diretamente para um desgaste na estrutura, reduzindo sua vida útil, podendo até gerar danos irreparáveis.

O estudo realizado teve como prerrogativa uma análise visual da edificação, baseada em referências bibliográficas, na qual foram constatadas as mais comuns manifestações patológicas como, fissuração, infiltração na cobertura e eflorescência. Dessa forma, conforme demonstrado anteriormente, uma das etapas construtivas que se mostraram críticas para o surgimento dessas manifestações patológicas é a impermeabilização. A negligência nesta etapa permite a ação de agentes externos no concreto, deteriorando o material por intermitência cíclica.

A falta de inspeção e manutenção na edificação feita por profissional capacitado, ocasiona na não solução dos problemas apresentados de forma adequada ou, inclusive, na não identificação do potencial causador da manifestação patológica. Para o caso em estudo, deve-se proceder com análises por meio de equipamentos para identificação das condições interna dos elementos estruturais para um diagnóstico mais amplo e melhor escolha da profilaxia adotada.

\section{REFERÊNCIAS}

ABNT (Associação Brasileira de Normas Técnicas). NBR 14931. Execução de estruturas de concreto - Procedimento, 2004.

BRANDÃO, A. M. S.; PINHEIRO, L. M. Qualidade e durabilidade das estruturas de concreto armado: aspectos relativos ao projeto. Cadernos de Engenharia de Estruturas. EESC. Universidade de São Paulo. São Carlos, 1999.

CASCUDO, O. Inspeção e Diagnóstico de Estruturas de Concreto com Problemas de Corrosão da Armadura. In.: Concreto: Ensino, Pesquisa e Realizações. Editor: Geraldo Cechella Isaia. São Paulo: IBRACON, 2005.

CASOTTI, D. E. Causas e Recuperação de Fissuras em Alvenaria. Universidade de São Francisco. Itatiba, 2007.

COUTO, J. P.; COUTO, A. M. Importância da revisão dos projetos na redução dos custos de manutenção das construções. In: CONGRESSO CONSTRUÇÃO 2007, 3, 2007, Coimbra, Portugal. Universidade de Coimbra, 2007.

DAL MOLIN, D.C.C. Fissuras em estruturas de concreto armado: análise das manifestações típicas e levantamento de casos ocorridos no estado do Rio Grande do Sul. Tese de M. Sc. - Curso de Pós-Graduação em Engenharia Civil, Universidade Federal do Rio Grande do Sul, Porto Alegre,1988. 
FIGUEIREDO, E. Terapia das Construções de concreto: Metodologia de avaliação de sistemas epóxi destinados à injeção de fissuras passivas das estruturas de concreto. 1989.

GONÇALVES, E.A.B. Estudo das Patologias e suas Causas nas Estruturas de Concreto Armado de Obras de Edificações. Projeto de Graduação. Universidade Federal do Rio de Janeiro. Rio de Janeiro, 2015.

HELENE, Paulo R. L. Manual de reabilitação de Estruturas de Concreto - Reparo, Reforço e Proteção. São Paulo: Red Rehabilitar, editores, 2003.

LotTermann, A. F. Patologias em Estruturas de Concreto: Estudo de Caso. Universidade Regional do Noroeste do Estado do Rio Grande do Sul. Ijuí, 2013.

MARCELLI, M. Sinistros na construção civil: causas e soluções para danos e prejuízos em obras. São Paulo: Pini, 2007.

SANTOS, C.F. Patologias de Estruturas de Concreto Armado. Projeto de Graduação. Universidade Federal de Santa Maria. Santa Maria, 2014.

SILVA, LKD; CABRAL, A. E. B. Levantamento de manifestações patológicas em estruturas de concreto armado no estado do Ceará. Monografia (Graduação em Engenharia Civil) - Universidade Federal do Ceará, Fortaleza, 2011.

SOUZA, V.; RIPPER, T. Patologia, Recuperação e Reforço de Estruturas de Concreto. São Paulo: Pini, 1998.

THOMAZ, E. Trincas em Edifícios: Causas, Prevenção e Recuperação. São Paulo: Pini, 1989.

TRINDADE, D. S. Patologia em Estruturas de Concreto Armado. 2015. Trabalho De Conclusão De Curso (Graduação em Engenharia Civil) - Centro De Tecnologia, Universidade Federal De Santa Maria, Santa Maria, 2015. 